\title{
Reverse osmosis pretreatment method for toxicity assessment of domestic wastewater using Vibrio qinghaiensis sp.-Q67
}

\author{
Xiaoyan Y. Ma ${ }^{a}$, Xiaochang C. Wang ${ }^{\mathrm{a}, *}$, Huu Hao Ngo ${ }^{\mathrm{b}}$, Wenshan Guo ${ }^{\mathrm{b}}$, \\ Maoni N. Wu ${ }^{a}$, Na Wang ${ }^{a}$ \\ ${ }^{\text {a }}$ Key Lab of Northwest Water Resources, Environment and Ecology, Ministry of Education, Xi'an University of \\ Architecture and Technology, Xi'an 710055, \\ China \\ b School of Civil and Environmental Engineering, Faculty of Engineering and Information Technology, University of \\ Technology Sydney, Broadway, NSW 2007, Australia \\ *Corresponding author. Fax: +86 29 82202125. E-mail addresses: xcwang45@hotmail.com, xcwang@xauat.edu.cn(X.C. \\ Wang)
}

Keywords: Domestic wastewater; Time-dependent toxicity; Vibrio qinghaiensis sp.-Q67; Reverse osmosis

\begin{abstract}
:
Luminescent bacterial test is a fast and sensitive method for acute toxicity assessment of water and wastewater. In this study, an improved toxicity testing method was developed using the freshwater luminescent bacteria Vibrio qinghaiensis sp.-Q67 that involved pretreatment of water samples with reverse osmosis (RO) to eliminate the interferences caused by nutrients in concentrated samples and to improve the reliability and sensitivity of the analysis. Because water samples contain low concentrations of several target toxic substances, rapid acute toxicity testing method that is commonly employed does not achieve enough sensitivity. The proposed RO pretreatment could effectively enrich organic and inorganic substances in water samples to enable a more effective and sensitive toxicity evaluation. The kinetic characteristics of toxicity of raw sewage and secondary effluent were evaluated based on the relative luminescence unit (RLU) curves and time-concentration-effect surfaces. It was observed that when the exposure time was prolonged to 8-h or longer, the bacteria reached the logarithmic growth stage. Hence, the stimulating effects of the coexisting ions (such as $\mathrm{Na}+, \mathrm{K}+, \mathrm{NO} 3-$ ) in the concentrated samples could be well eliminated. A 10-h exposure time in proposed Q67 test was found to quantitatively evaluate the toxicity of the organic and inorganic pollutants in the RO-concentrated samples.
\end{abstract}

\section{Introduction}

Ecotoxicity is an index to reflect the impact of pollutants on environment and human health (Bundschuh and Schulz, 2011). In the formulation of laws and regulations, ecotoxicity control is one of the effective approaches from the viewpoint of aquatic environ- ment protection (Mendonca et al., 2009), especially when a water body is receiving effluent discharge from wastewater treatment plants (Bundschuh et al., 2011). In many countries ecotoxicity monitoring has already been adopted routinely for wastewater management (Hernando et al., 2005; Carafa et al., 2011).

Compared to chemical analysis targeting individual pollutants, ecotoxicity is a measure of the integrated toxic effects of all the pollutants on aquatic fauna and flora. The toxicity is usually tested by bioassays using chosen aquatic organisms that are sensitive to toxic substances. If the detection limit of the bioassay is suffi- ciently low or the concentration of the toxic substances in the testing sample is sufficiently high, it is preferable to use the original water sample for the toxicity tests to avoid any change in the chemical composition. However, in many cases the con- centration of the toxic substances in the test sample is very low and the sensitivity of toxicity test may be much affected by the coexisting nutrient salts that often have strong stimulating effects on the bioassay (Ore et al., 2007; Macken et al., 2008). Therefore, sample pretreatment is often required for isolating and/or concentrating the target toxic substances and eliminating the interference.

When organic substances are the targets of ecotoxicity test, liquid-liquid extraction (Pérez et al., 2009), resin adsorption (Reginatto et al., 2009) and solid-phase extraction (SPE) (Dagnino et al., 2010; Smital et al., 2011) are the common pretreatment methods for effective extraction of organic substances and elimination of all inorganic interferences. If heavy metals become the target substances, passive sampling can effec- tively concentrate the metals ions by utilizing diffusive gradient in thin-films (Roig et al., 2011). However, the ecotoxicity test should virtually be an integrated evaluation of the ecotoxic effects of all possible toxic substances in the water sample. Any loss of either inorganic or organic toxic substances following these methods will affect the reliability of the test. 
Therefore, it needs to find a way to concentrate a lowconcentration sample without much change in its chemical composition.

For the ecotoxicity test, the bioassay using luminescent bacteria has been recognized as a useful method for its short testing time, good sensitivity and reproducibility (Mantis et al., 2005; Parvez et al., 2006; Ye et al., 2011). The mechanism of the luminescence emission is that luciferase catalyzes oxidation reaction of the reduced state flavin mononucleotide $\left(\mathrm{FMNH}_{2}\right)$ to the oxidized state (FMN) accompanying light release, which is closely related to the bacterial metabolism (Girotti et al., 2008). Any factors that may affect the bacterial metabolism will have effect on the luminescence emission. When the luminescent bacteria are exposed to toxic substances, the metabolism of luminescent bacterium will be disturbed so that the light emission is weakened. By measuring the luminescence before and after a certain exposure time, the toxicity can be quantitatively evaluated using a bioluminescence inhibition value (Zhou et al., 2010). In a water sample, some inorganic matter such as nutrient salts may promote the respiration of the luminescent bacteria, and stimulate light emission (Rosal et al., 2010). Thus, to assure the reliability of toxicity tests, the method for decreasing the stimulating effect from these interference substances is also an essential study.

Due to the relatively short generation cycle of bacteria, the exposure time for the bioassay using luminescent bacteria is often set as shorter as $15 \mathrm{~min}$ and the toxicity is taken as the acute toxicity (ISO 11348, 2008). However, the time-dependent toxicity of herbicides, pentachlorophenol and chloramphenicol etc. in the chronic toxicity assay has also been identified using luminescent bacteria (Froehner et al., 2002; Zhu et al., 2009). Therefore, the time-dependent toxicity assay using luminescent bacteria may need further investigation especially for practical water samples for which little information is available.

In this study, the main objective was to develop a pretreatment procedure in order to improve the sensitivity of the luminescent bacterial assay for toxicity assessment. A new scheme of bioassay was thus proposed with prolonged exposure of the luminescent bacteria Vibrio qinghaiensis sp.-Q67 (Q67) to the substances in water samples from a domestic wastewater treatment plant (WWTP) concentrated by reverse osmosis (RO). The kinetic characteristics of toxicity of raw sewage and secondary effluent were also analyzed.

\section{Materials and methods}

2.1. Sample collection and preparation

Raw sewage and secondary effluent samples were collected from a WWTP in Xi'an, China where an oxidation ditch process was applied. The sampling was conducted when the WWTP was operated under normal weather and operational conditions. The collected samples were firstly filtered by a $0.45 \mu \mathrm{m}$ mixed cellulose ester membrane mounted on a stainless steel single filter holder $(\Phi 150 \mathrm{~mm})$ to remove the suspended solids. The membrane was boiled in Milli-Q water before use and the filtrate of the first batch was discarded.

A series of inorganic salt solutions were also prepared for a preliminary experiment to compare the recoveries of different cationic and anionic ions by RO concentration. The target cationic ions were $\mathrm{Na}^{+}, \mathrm{Ca}^{2+}$ and $\mathrm{Al}^{3+}$, and anionic ions were $\mathrm{Cl}^{-}, \mathrm{NO}_{3}{ }^{-}$and $\mathrm{SO}_{4}{ }^{2-}$. For this purpose, $\mathrm{NaCl}, \mathrm{CaCl}_{2}, \mathrm{AlCl}_{3}, \mathrm{NaNO}_{3}$ and $\mathrm{Na}_{2} \mathrm{SO}_{4}$ salts of analytic grade were used and solutions were prepared by dissolving each of these salts into deionized water.

\subsection{Sample concentration}

For concentrating organic and inorganic substances from water samples, a RO device (MSM-2008, Mosu Co. Shanghai, China) was used. The $0.45 \mu \mathrm{m}$ filtered sample was pumped into the RO device where the permeated solution was discharged and the concentrate was sent back to the sample reservoir, thus forming a circulating flow for continuous concentrating the sample until it reached the prescribed concentration. The final concentrate was collected for subsequent time-dependent toxicity test. After each batch of concentrating operation, the RO membrane module was firstly washed with $0.1-0.2$ percent $\mathrm{NaOH}$ solution and then with purified water. The final concentration fold of the concentrated sample was calibrated by measuring the total organic carbon (TOC) concentration before and after RO concentration using Shimadzu TOC-VC, Japan. The ionic concentration of the sample was estimated by conductivity measurement using HQ30d (HACH, USA). The concentrated samples were stored at $4{ }^{\circ} \mathrm{C}$ for later use.

To concentrate only the organic substances from the water samples, SPE was conducted following the authors' previous work (Ma et al., 2011).

\subsection{Q67 toxicity test}

For the toxicity test, the Q67 luminescent bacteria purchased from Beijing Hammatsu Photon Techniques Inc. was grown in a culture medium that could produce larger quantity of bacteria with fluorescence enzyme (Ma et al., 2012). The bacteria were inoculated from the stock culture medium maintained at $4{ }^{\circ} \mathrm{C}$ to a $50 \mathrm{ml}$ liquid medium and grown up to the logarithmic growth stage after 10 to $12 \mathrm{~h}$ under $2271^{\circ} \mathrm{C}$ while shaking at $120 \mathrm{rpm}$.

The toxicity test was conducted in two ways. One was the acute toxicity test with exposure time as 15 min following the authors' previous work (Ma et al., 2011). Another was the toxicity test with exposure time prolonged up to $12 \mathrm{~h}$, and operation procedures as below.

The grown-up Q67 bacteria from the liquid medium were used as the inoculum for the time-dependent bioassay performed on Centrol IApc LB962 Microplate Luminometer (Berthold Technologies Company, Germany). The initial RLU was controlled in the range of $3 \times 10^{6}-4 \times 10^{6}$. For each concentrated water sample, ten testing solutions with gradient diluting ratios were prepared and each solution was tested in three parallels plus one blank control which were placed in the wells of the 96-well Microplate (Corning, American). In each of the wells, the volume ratio of the inoculum, two-fold concentrated medium and the testing solution (or blank) was 1:4:5, and the final test volume was $200 \mu \mathrm{l}$. All the marginal wells were filled with $200 \mu \mathrm{l} \mathrm{Milli-Q}$ water to avoid marginal effect on the accuracy of the measurement. The microplate was incubated at $22{ }^{\circ} \mathrm{C}$ for $12 \mathrm{~h}$ with RLU measurement in every $30 \mathrm{~min}$. Eq. (1) was used for calculating the integral inhibition value (Zhu et al., 2009).

Inhibition $_{m}$ (percent) $=\left(1-\frac{\sum_{i=0}^{m-1}\left(L t_{i+1}+L t_{i}\right)}{\sum_{i=0}^{m-1}\left(L C t_{i+1}+L C t_{i}\right)}\right) \times 100$

where Inhibition $m_{m}$ is the integral inhibition value at time $t_{m}$ (percent), $L_{t}$ is the average RLU of the parallel testing solutions at time $t_{i}$, and $L C t_{i}$ is the average RLU of the controls at time $\mathrm{t}_{\mathrm{i}}$.

Eq. (1) is suitable for evaluating the response of exposure time on light inhibition in the time-dependent ecotoxicity test. The time-concentrationresponse (integral inhibition value) surface diagrams were designed to show the three-dimensional (3D) experience. Contrast to integral inhibition, for the acute toxicity text the exposure time was fixed as $15 \mathrm{~min}$ and the inhibition value could be calculated as Eq. (2)

I(percent $)=\frac{R_{0}-R}{R_{0}} \times 100$

where $\mathrm{I}$ is the inhibition value (percent), $\mathrm{R}$ and $\mathrm{R}_{0}$ are the average RLU values of the parallel samples and the controls, respectively, after 15 min exposure.

To obtain the growth curve of the Q67 bacteria, the optical density of bacteria suspension was measured using a spectrophotometer (UV-1650PC, Shimadzu, Japan) at a wavelength of $600 \mathrm{~nm}$.

\section{Results and discussion}

\subsection{Recovery of inorganic and organic substances by RO-concentrating}

To evaluate how inorganic and organic substances could be recovered by RO-concentrating, a preliminary experiment was conducted using solutions of known concentrations of $\mathrm{NaCl}, \mathrm{CaCl}_{2}$ and $\mathrm{AlCl}_{3}$ for comparing the recoveries of different cationic ions, and that of $\mathrm{NaCl}, \mathrm{NaNO}_{3}$ and $\mathrm{Na}_{2} \mathrm{SO}_{4}$ to compare the recoveries of different anionic ions. The secondary effluent collected from the WWTP was also used for comparing the recoveries of ions and organic substances from practical samples. Each of these samples was firstly pumped into the RO device where the permeated and concentrated solutions were separately collected. The concentrated solution was then sent to the RO device for the next round of concentrating operation. Similar operation was repeated four rounds. In each round, the volumes, conductivity, and/or TOC concentration of the permeated solutions were measured to 
calculate the percents of inorganic ions and/or organic substances which could be recovered by RO-concentrating.

As shown in Table 1, for each of the solutions, after ROconcentrating for 2 or 3 rounds the percent of unrecoverable ions tended to be stable. Although there were differences between different solutions, all the recovery rate (percent) were at high percentage even for the $\mathrm{NaCl}$ solution with the lowest atomic weight for the monovalent cation $\mathrm{Na}^{+}$and that for the monovalent anion $\mathrm{Cl}^{-}$. The $\mathrm{NaNO}_{3}$ solution showed the lowest recovery rate, but it was still 97.57 percent. Regarding the secondary effluent, the recovery of inorganic ions were more than 99 percent and that of the organic substances were more than 97 percent, indicating a good recovery of all substances by RO-concentrating.

Evaluation of the recovery of inorganic and organic substances by RO-concentrating.

RO has been widely used for concentrating dissolved organic substances and for water desalination (Pernet-coudrier et al., 2008; Zhou et al., 2011; El-Ghonemy, 2012). It is reported that a 98.8 percent salt recovery could be achieved by RO (Qu et al., 2009) and the recovery of dissolved organic substances ranged from 91 to 98 percent (Croue, 2004). The percentages of the recoverable substances calculated from Table 1 were approximately within the reported range, indicating that ROconcentrating tended to be non-selective for concentrating both inorganic and organic substances so that the loss of toxic constituents in the concentrating process could be effectively controlled. For example, the isolation and concentration of organic substances often depend on their selective adsorption property on chemical media and/or solubility in chemical solvents. In such cases, not only the inorganic constituents but also a high percent of organic matter may be lost. It was reported that only 12-36 percent of the total organic amount can be recovered by SPE (Baun et al., 2004; Boleda et al., 2009; Wang et al., 2011). Furthermore, Cao et al. (2009) indicated that RO could achieve remarkable removals of genotoxic effect, acute toxicity and retinoic acid receptor agonist activity from secondary effluent. In other words, most of the toxic substances in water samples were retained in the RO concentrate. Hence, it is an effective method to use RO to concentrate water samples for bioassays.

\subsection{Concentration- and time-response characteristics of Q67 tests}

\subsubsection{Concentration- and time-response of RLU curves}

The collected raw sewage and secondary effluent samples were concentrated using the RO device and time-dependent toxicity tests were conducted. Fig. 1 shows the concentration- and timeresponse of RLU for the raw sewage and secondary effluent samples. It can be seen that with the samples concentrated by different folds, there was almost no increase in the initial RLU

Table 1

Evaluation of the recovery of inorganic and organic substances by RO-concentrating.

\begin{tabular}{|c|c|c|c|c|c|c|}
\hline \multirow[t]{2}{*}{ Solution } & \multirow{2}{*}{$\begin{array}{l}\text { Concentration } \\
(\mathrm{mg} / \mathrm{l})\end{array}$} & \multirow{2}{*}{$\begin{array}{l}\text { Conductivity } \\
(\mu \mathrm{S} / \mathrm{cm})\end{array}$} & \multicolumn{4}{|c|}{ Recovery rate (\%) } \\
\hline & & & $\begin{array}{l}\text { First } \\
\text { round }\end{array}$ & $\begin{array}{l}\text { Second } \\
\text { round }\end{array}$ & $\begin{array}{l}\text { Third } \\
\text { round }\end{array}$ & $\begin{array}{l}\text { Fourth } \\
\text { round }\end{array}$ \\
\hline $\mathrm{NaCl}$ & 300 & 613 & 99.71 & 99.30 & 99.27 & 99.20 \\
\hline $\mathrm{CaCl}_{2}$ & 300 & 630 & 99.67 & 98.93 & 98.96 & 98.93 \\
\hline $\mathrm{AlCl}_{3}$ & 250 & 660 & 99.25 & 98.19 & 98.19 & 98.43 \\
\hline $\mathrm{NaCl}$ & 300 & 613 & 99.71 & 99.30 & 99.27 & 99.20 \\
\hline $\mathrm{NaNO}_{3}$ & 450 & 609 & 99.39 & 98.42 & 97.74 & 97.57 \\
\hline $\mathrm{Na}_{2} \mathrm{SO}_{4}$ & 400 & 646 & 99.88 & 99.76 & 99.81 & 99.78 \\
\hline Secondary & - & 749 & 99.72 & 99.02 & 99.10 & 99.10 \\
\hline effluent & 2.519 (TOC) & - & 100 & 100 & 98.82 & 97.97 \\
\hline
\end{tabular}

within 6-h exposure time. However, a sharp rise of RLU was observed for the samples of different concentration folds after $6 \mathrm{~h}$. As time elapsed, the more highly concentrated samples inhibited luminescence more than the control sample did.

Fig. 2 shows the growth curve of Q67 in pure culture medium, where OD600, the light absorbance at $600 \mathrm{~nm}$, was used as a parameter to characterize the density of the bacteria in the suspension. There was apparently a lag time about $6 \mathrm{~h}$ before the OD600 value started to increase, implying that the bacteria needed certain time to adapt to the environment in the culture medium. A logarithmic growth stage could be seen between $8 \mathrm{~h}$ to $12 \mathrm{~h}$ as indicated by the straight line on the graph. By comparing Fig. 2 with Fig. 1, it appears that in the exposure of Q67 bacteria to the water samples, the concentration- and time-response of RLU was closely related to the growth of the bacteria in the culture media. Without fast bacteria growth in the first $6 \mathrm{~h}$, there was hardly recognisable response of RLU to the concentration of toxic substances in the water samples. The bacteria in the logarithmic growth stage would metabolize boomingly and quickly consume the nutrients in the culture media thus leading to an increase of RLU. The presence of toxic substances, as in the case of highly concentrated water samples, would retard metabolism and the

a

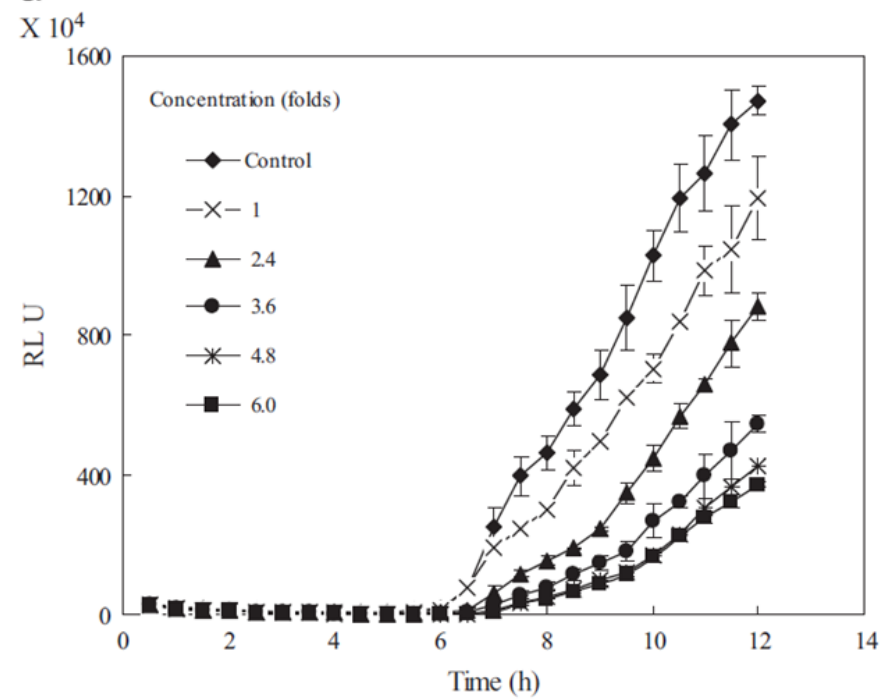

b

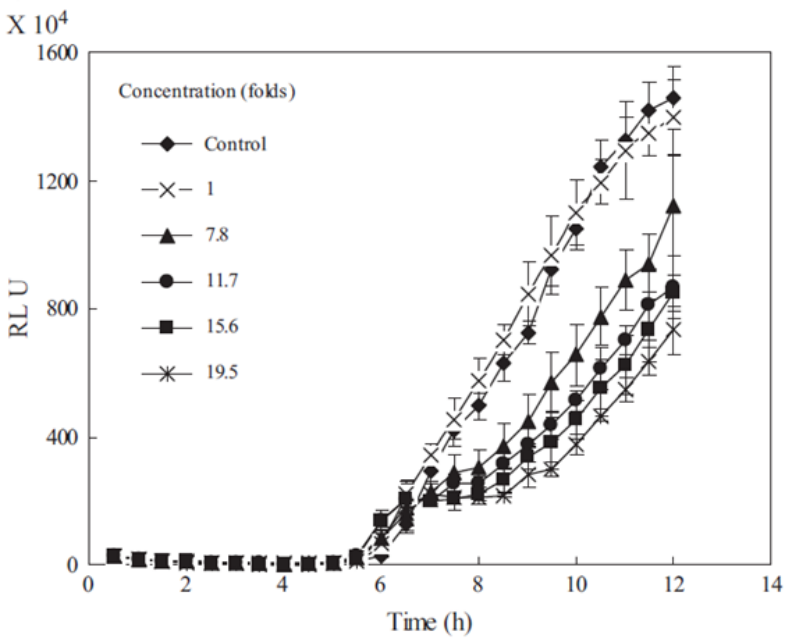

Fig. 1. Concentration- and time-response of RLU for raw sewage (a) and secondary effluent (b). 



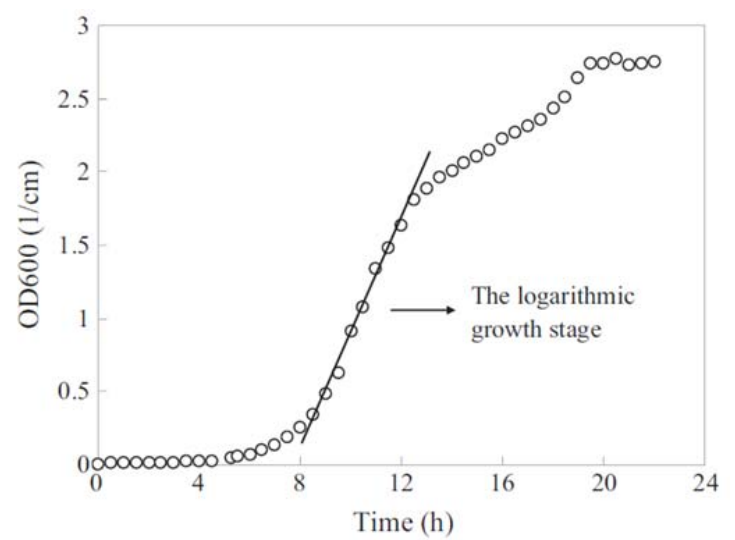

Fig. 2. The growth curve of Q67 bacteria.

luminescence would also be inhibited so that the RLU value became lower than that of the control sample (Utgikar et al., 2004; Zhang et al., 2008). After $12 \mathrm{~h}$, the growth rate of bacteria slowed down due to the exhaustion of nutrients in the culture media.

\subsubsection{Three-dimensional inhibition surfaces}

By calculating the integral inhibition value using Eq. (1) and drawing a 3D (time-concentration-response) graph to show its relation with time and concentration folds, Fig. 3 indicates the kinetic characteristic of toxicity over the incubation time and provides more intuitive information about the response of luminescent bacteria. The different shape of surface could reflect different toxicity effect of water samples on organisms. For the raw sewage, the initial inhibition tended to be negative at low concentration folds possibly due to the stimulating effect of interference substances such as inorganic salts (Schneyer, 1951; Deriabin and Aleshina, 2008). At higher concentration folds, positive inhibition was observed but the value was still very low. This shows that acute toxicity test (exposure time as $15 \mathrm{~min}$ ) might not be sensitive enough for the water samples concentrated by RO. The coexisting inorganic substances, such as nutrient salts, apparently interfered with the toxicity evaluation in short exposure time. Nevertheless, after the time of $6 \mathrm{~h}$, a steeply sloped surface appeared on the graph. The surface finally reached the stable stage after the time of $8 \mathrm{~h}$.

Comparing with the 3D surface for the raw sewage samples, the 3D surface for the secondary effluent samples showed different features where a "valley" appeared between the times of 5 and $7.5 \mathrm{~h}$. The bottom of the valley could reach an inhibition value of -80 percent, indicating a very strong stimulating effect. After this point the surface went up sharply and finally became stable after the time of 9 or $10 \mathrm{~h}$.

\subsection{Determination of exposure time for the specific toxicity test}

Although the development of the toxicity along with the bacteria reproduction could be observed from the 3D surface graph, more detailed information could only be obtained by comparing the toxicity levels of different samples. In order to quantitatively evaluate the time-dependent toxicity using the luminescent bacteria, a suitable exposure time should be selected. Fig. 4 was plotted using the data of inhibition values and sample concentrations at 9,10 and $11 \mathrm{~h}$ for the raw sewage and secondary effluent samples. As can be seen in Fig. 4a that for the raw sewage samples, the inhibition-concentration relationships did not differ much at 9, 10 and $11 \mathrm{~h}$, while for the secondary effluent samples (Fig. 4b), lower inhibition values were shown at $9 \mathrm{~h}$ than that at 10 and $11 \mathrm{~h}$. Therefore, $10 \mathrm{~h}$ seemed to be a suitable exposure time for the quantitative analysis of toxicity test. By statistical calculation of the data at $10 \mathrm{~h}$ following a Logistic distribution, regressive curves were obtained as shown in Fig. 4. The effective concentrations corresponding to 50 percent inhibition, i.e. $\mathrm{EC}_{50}$ were evaluated as 2.1 folds and 16.1 folds, respectively, for the raw sewage and secondary effluent. The great difference between the $\mathrm{EC}_{50}$ values was an indication of the effectiveness of biological treatment in reducing the ecotoxicity of the domestic wastewater.

\subsection{Interference of coexisting inorganic ions on acute and time- dependent toxicity tests}

Both organic and inorganic pollutants in water samples could be concentrated by RO-concentrating. This may effectively prevent the loss of toxic substances and increase the reliability of the toxicity test from the viewpoint of integrated evaluation of the overall ecotoxicity caused by any organic or inorganic substance that possibly have toxic effects. On the other hand, as ROconcentrating could also enrich most of the non-toxic inorganic salts, their stimulating effects on the luminescent bacteria may affect the reliability of the test (Abbondanzi et al., 2003).
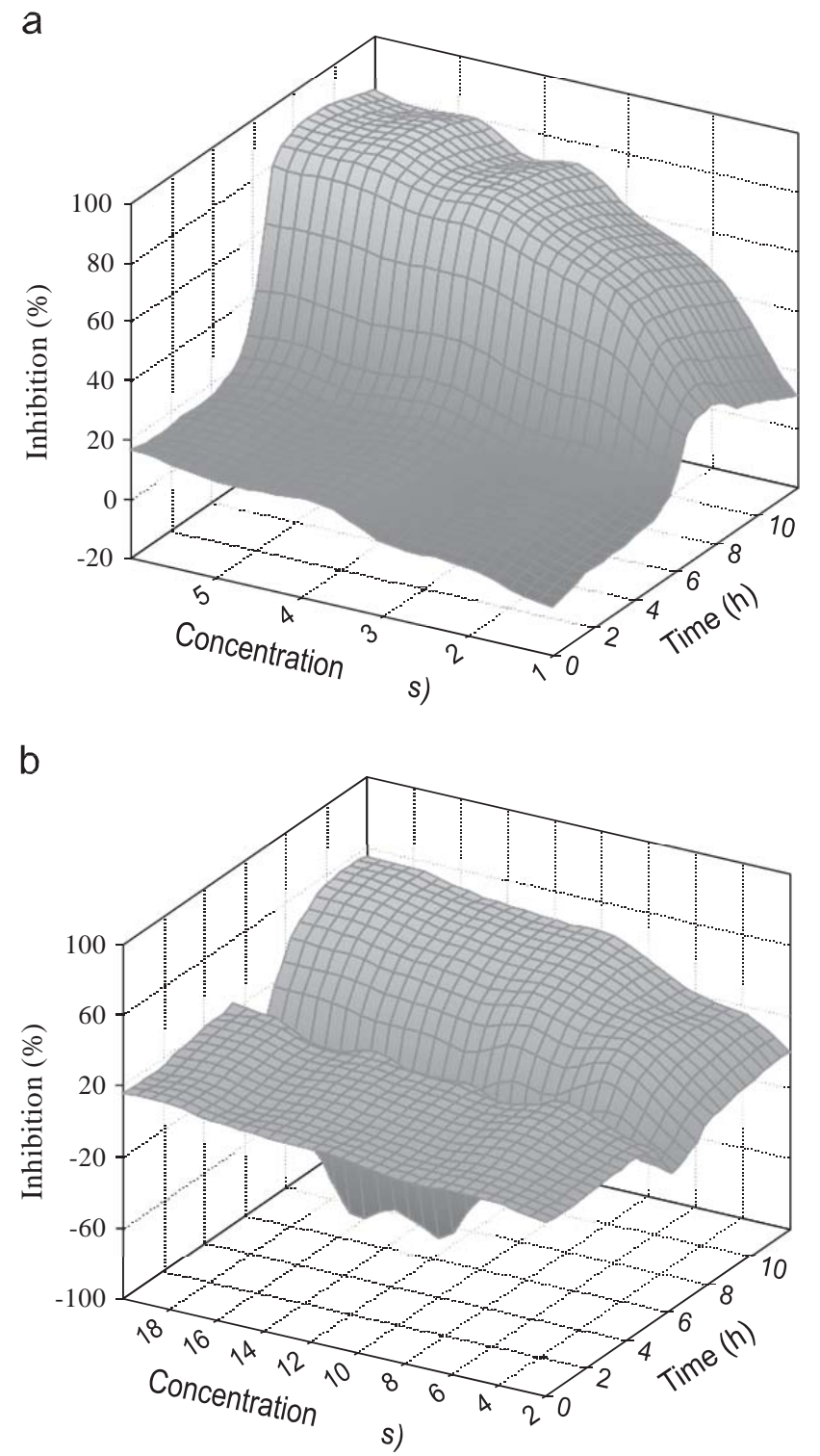

Fig. 3. 3D inhibition surfaces for raw sewage (a) and secondary effluent (b). 
To understand how the coexisting salts can affect the toxicity tests, an experiment was conducted by using raw sewage samples pretreated by SPE with and without addition of $\mathrm{NaNO}_{3}$ to a concentration of $300 \mathrm{mg} / \mathrm{l}$ for acute (15 $\mathrm{min})$ and time-dependent $(10 \mathrm{~h})$ toxicity tests.

As can be seen from Fig. 5a, for the acute toxicity test without $\mathrm{NaNO}_{3}$ addition, there was no negative inhibition shown, while with the addition of $300 \mathrm{mg} / \mathrm{NaNO}_{3}$, the inhibition values was negative until the sample was concentrated to over 15 folds, exhibiting a very strong stimulating effect of the coexisting salt on the acute toxicity test. It indicated that the $\mathrm{EC}_{50}$ value could not be correctly evaluated from the inhibition-concentration relationships which differed much under the conditions with and without coexisting salts. However, for the toxicity test with the exposure time prolonged to $10 \mathrm{~h}$ (Fig. 5b), the stimulating effect due to $\mathrm{NaNO}_{3}$ addition was significantly reduced. The inhibition-concentration relationships were not much difference under the conditions with and without coexisting salts so that the $\mathrm{EC}_{50}$ value could be more reliably evaluated. The toxicity test with a $10 \mathrm{~h}$
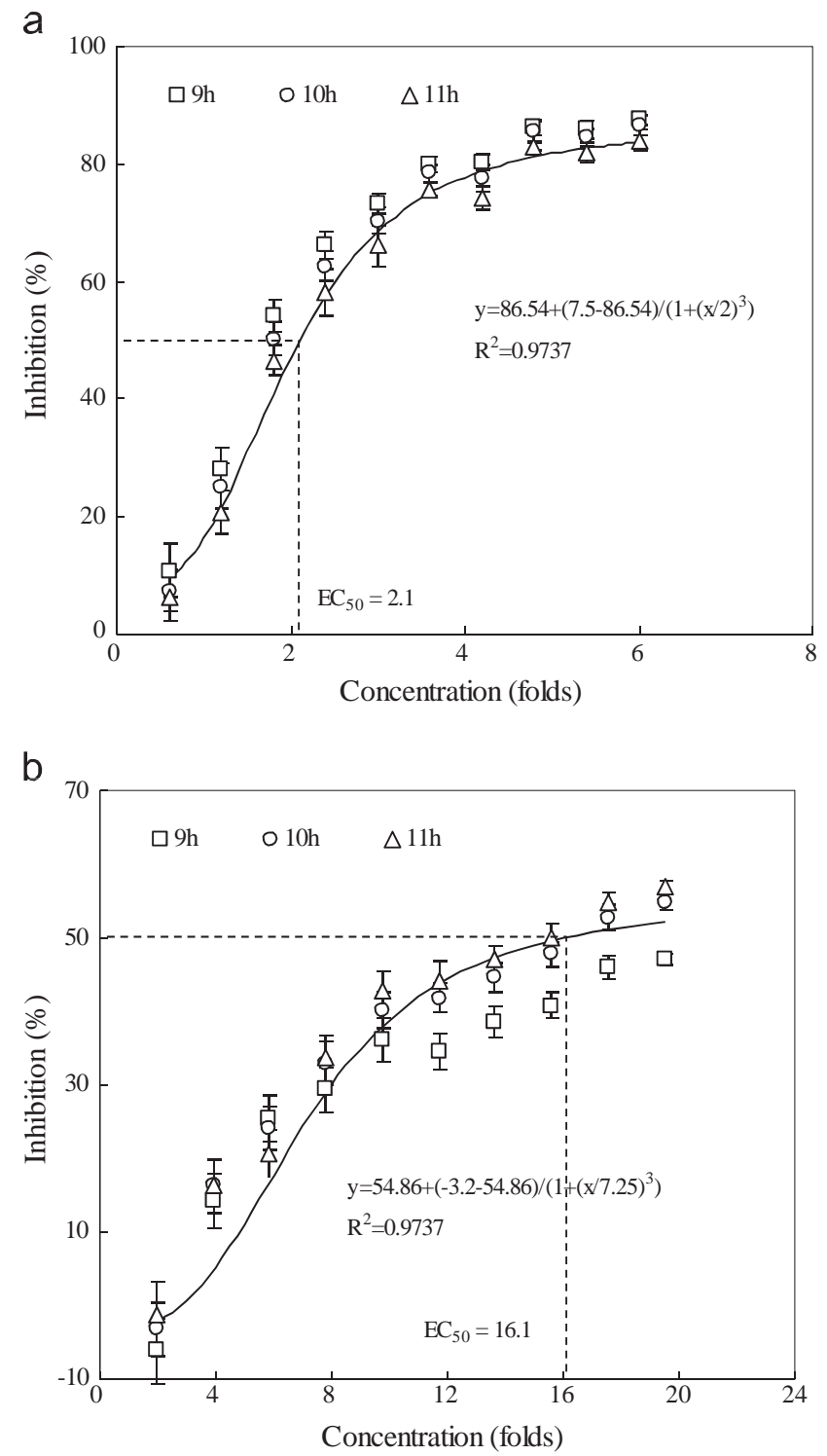

Fig. 4. Comparison of exposure times for time-dependent toxicity test for raw sewage (a) and secondary effluent (b) (curves with statistical calculation are for $10 \mathrm{~h}$ exposure). exposure time seemed to be much less sensitive to the interference of the coexisting salts.

By comparing Fig. 4a and Fig. 5b where the inhibition-concentration relationships were obtained by the time-dependent toxicity tests for the same raw sewage but using different ways for sample concentration (RO-concentrating for Fig. 4a but SPEconcentrating for Fig. 5b), it was noticeable that the values of $\mathrm{EC}_{50}$ obtained were about 1 order different from each other. The much higher value of $\mathrm{EC}_{50} 1 / 424.3$ obtained from Fig. $5 \mathrm{~b}$ seemed to be an underestimation of the toxic level of the raw sewage due to the loss of all inorganic substances and non-extractable organic substances by SPE pretreatment comparing with the much lower value of $\mathrm{EC}_{50} 1 / 42.1$ obtained from Fig. 4a when most of the inorganic and organic substances were concentrated by RO pretreatment. For an overall evaluation of the ecotoxicity from all possible toxic substances, RO would be more appropriate to be applied for sample pretreatment prior to the time-dependent toxicity test.

\subsection{Advantages of the specific toxicity assessment}

Bioassay using luminescent bacteria is a simple method for an integrated evaluation of the toxic effects of pollutants on water environment. The importance for ensuring the effectiveness of

a
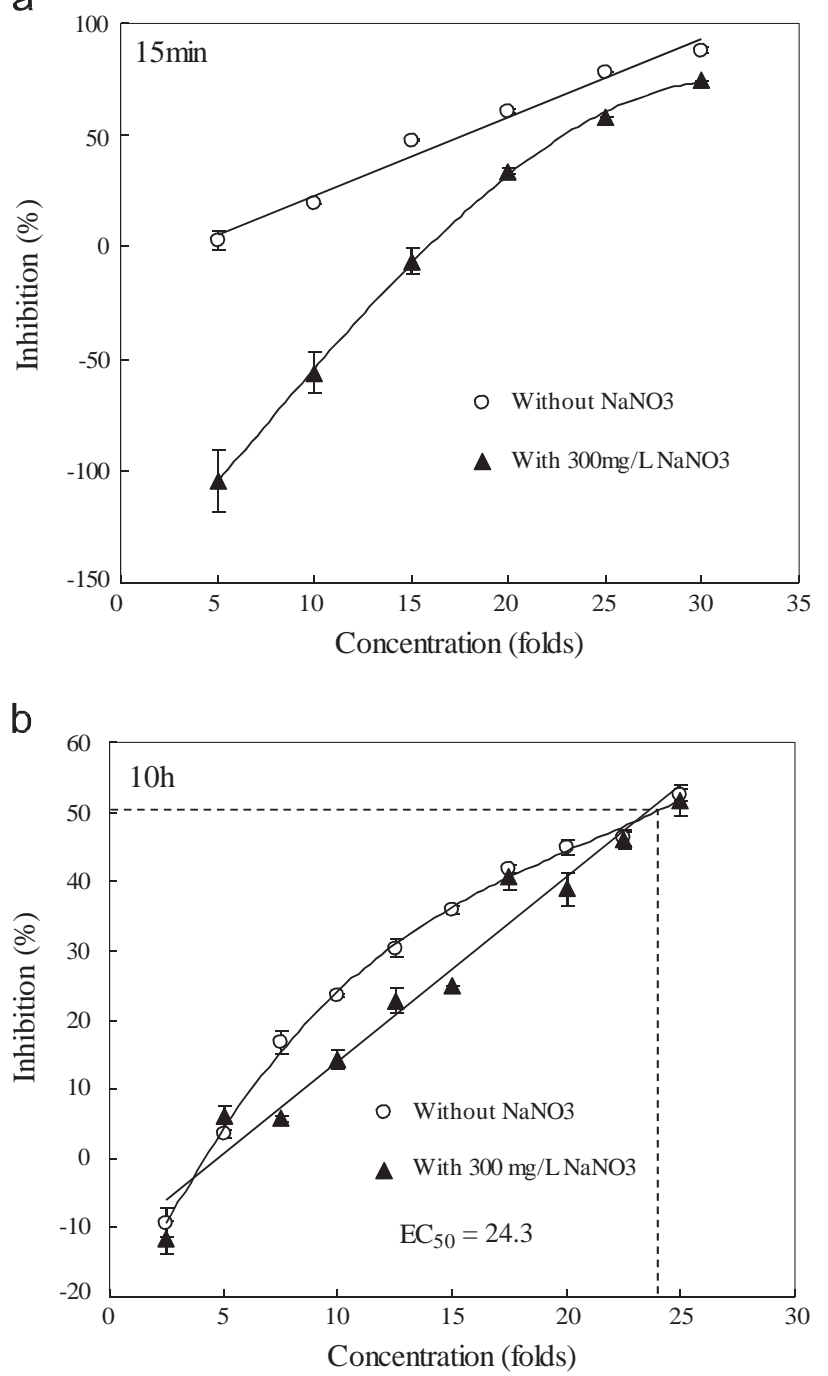

Fig. 5. Interference of $\mathrm{NaNO}_{3}$ on acute toxicity test (a) and toxicity test with an exposure time of $10 \mathrm{~h} \mathrm{(b).}$ 
such kind of toxicity tests is to let the luminescent bacteria be exposed to all possible toxic substances at a concentration sufficiently high so as to acquire reliable response. Therefore, sample pretreatment for concentrating the pollutants is an indispensible step prior to the bioassay (Galassi et al., 2004).

For acute toxicity test, both the raw sewage and secondary effluent (without concentrating) samples showed no obvious inhibition effect on Q67 at the exposure time of 15 min. However, for the time-dependent toxicity test, all the raw sewage samples (concentration fold as 1 in Fig. 1) showed certain toxic effects on luminescent bacteria, while all the secondary effluent samples still did not show any inhibition effects comparing with the control sample. This indicated that the time-dependent toxicity test was more sensitive than the acute toxicity test with exposure time for $15 \mathrm{~min}$. The phenomena were similar to what happened in Daphnia magna chronic and acute toxicity test (Dom et al., 2012). The mechanism of the time-dependent toxicity test would be virtually different from that of the acute toxicity test (Zou et al., 2012). It could also be seen from Fig. 1 that as the samples were concentrated by RO (concentration fold larger than 1), the RLU curves went down apparently with increasing concentration fold, indicating that the sensibility of the toxicity test was much improved by combining the time-dependent toxicity test with RO pretreatment.

$\mathrm{RO}$ is by virtue a process to enrich all the organics and most of the inorganic substances in the concentrate. Only few of the monovalent ions such as $\mathrm{Na}^{+}$and $\mathrm{Cl}^{-}$, which may not be suspicious of toxic, may penetrate the RO membrane. From Table 1, it was noticeable that the recovery could be as high as 98 to 99 percent, indicating that most of the organic and inorganic substances were enriched so that the loss of the target toxic substances could be well prevented. However, RO pretreatment is inevitably associated with the enrichment of nutrient salts in the concentrated samples which may stimulate the metabolic activity of the luminescent bacteria. As a result, unexpected emission of luminescence may occur and the true luminescence resulting from the toxic substances may be inhibited (Rosal et al., 2010). In this case, the acute toxicity measurement of $15 \mathrm{~min}$ exposure may not be valid at all.

To overcome such a difficulty, the specific toxicity assessment procedure proposed in this study is a time-dependent toxicity test by prolonging the exposure time of the Q67 bacteria to the concentrated sample to 9-11 h in which the Q67 bacteria can undergo several generations so that the excess nutrient salts can be consumed by bacteria growth. The time-dependent toxicity finally evaluated is just after the consumption of all these inhibiting substances and the toxic effect can reliably reflect the integrated toxicity of contaminants in the testing samples.

\section{Conclusions}

The proposed toxicity assessment combining the time-dependent toxicity test using Q67 with RO was proven to be an applicable method for improving the reliability and sensitivity of the ecotoxicity test. The preliminary experiment showed that RO operation could effectively concentrate the organic and inorganic substances in a water sample, so that an integrated toxicity assessment is applicable. Through evaluating the toxicity of raw sewage and secondary effluent in a WWTP using this method, some specific findings obtained are as follows:

(1) A 10-h exposure time was optimal for the quantitative analysis of time-dependent toxicity of domestic wastewater, indicating that biological treatment could effectively reduce the ecotoxicity of the domestic wastewater.
(2) By prolonging the exposure time to $10 \mathrm{~h}$, the stimulating effects of the coexisting salts such as $\mathrm{NaNO}_{3}$ could be effectively reduced and more reliable results could be obtained.

(3) The time-concentration-effect surfaces of raw sewage and secondary effluent showed different shapes, reflecting different toxicity effect of water samples on organisms.

\section{Acknowledgments}

This work were supported by the National Natural Science Foundation of China (No. 50838005), the Program for Changjiang Scholars and Innovative Research Team in University (No. IRT0853) and the Program for Innovative Research Team in Shaanxi Province (PIRT) (Grant No. 2013KCT-13).

\section{References}

Abbondanzi, F., Cachada, A., Campisi, T., Guerra, R., Raccagni, M., Iacondini, A., 2003. Optimisation of a microbial bioassay for contaminated soil monitoring: bacterial inoculum standardisation and comparison with Microtox ${ }^{\mathrm{s}}$ assay. Chemosphere 53, 889-897.

Baun, A., Ledin, A., Reitzel, L.A., Bjerg, P.L., Christensen, T.H., 2004. Xenobiotic organic compounds in leachates from ten Danish MSW landfills-chemical analysis and toxicity tests. Water Res. 38, 3845-3858.

Boleda, M.R., Galceran, M.T., Ventura, F., 2009. Monitoring of opiates, cannabinoids and their metabolites in wastewater, surface water and finished water in Catalonia, Spain. Water Res. 43, 1126-1136.

Bundschuh, M., Schulz, R., 2011. Ozonation of secondary treated wastewater reduces ecotoxicity to Gammarus fossarum (Crustacea; Amphipoda): are loads of (micro)pollutants responsible? Water Res. 45, 3999-4007.

Bundschuh, M., Zubrod, J.P., Seitz, F., Stang, C., Schulz, R., 2011. Ecotoxicological evaluation of three tertiary wastewater treatment techniques via meta-analysis and feeding bioassays using Gammarus fossarum. J. Hazard. Mater. 192, 772778.

Cao, N., Yang, M., Zhang, Y., Hu, J., Ike, M., Hirotsuji, J., Matsui, H., Inoue, D., Sei, K., 2009. Evaluation of wastewater reclamation technologies based on in vitro and in vivo bioassays. Sci. Total Environ. 407, 1588-1597.

Carafa, R., Faggiano, L., Real, M., Munné, A., Ginebreda, A., Guasch, H., Flo, M., Tirapu, L., der Ohe, P.C.V., 2011. Water toxicity assessment and spatial pollution patterns identification in a Mediterranean River Basin District. Tools for water management and risk analysis. Sci. Total Environ. 409, 4269-4279.

Croue, J.P., 2004. Isolation of humic and non-humic NOM fractions: structural characterization. Environ. Monit. Assess. 92, 193-207.

Dagnino, S., Gomez, E., Picot, B., Cavaillès, V., Casellas, C., Balaguer, P., Fenet, H., 2010. Estrogenic and AhR activities in dissolved phase and suspended solids from wastewater treatment plants. Sci. Total Environ. 408, 2608-2615.

Deriabin, D.G., Aleshina, E.S., 2008. Effect of salts on luminescence of natural and recombinant luminescent bacterial biosensors. Appl. Biochem. Microbiol 44, 324-329.

Dom, N., Penninck, M., Knapen, D., Blust, R., 2012. Discrepancies in the acute versus chronic toxicity of compounds with a designated narcotic mechanism. Chemosphere 87, 742-749.

El-Ghonemy, A.M.K., 2012. A small-scale brackish water reverse-osmosis desalination system used in northern Saudi Arabia: a case study. Renewable Sustainable Energy Rev. 16, 4597-4605.

Froehner, K., Meyer, W., Grimme, L.H., 2002. Time-dependent toxicity in the longterm inhibition assay with Vibrio fischeri. Chemosphere 46, 987-997.

Galassi, S., Guzzella, L., Croce, V., 2004. Screening organic micropollutants in surface waters by SPE extraction and ecotoxicological testing. Chemosphere 54, 16191624.

Girotti, S., Ferri, E.N., Fumo, M.G., Maiolini, E., 2008. Monitoring of environmental pollutants by bioluminescent bacteria. Anal. Chim. Acta 608, 2-29.

Hernando, M.D., Fernández-Alba, A.R., Tauler, R., Barceló, D., 2005. Toxicity assays applied to wastewater treatment. Talanta 65, 358-366.

ISO 11348-2008, Water Quality_Determination of the Inhibitory Effect of Water Samples on the Light Emission of Vibrio fischeri (Luminescent bacteria test), European Norm.

Ma, X.Y., Wang, X.C., Liu, Y.J., 2011. Study of the variation of ecotoxicity at different stages of domestic wastewater treatment using Vibrio-qinghaiensis sp.-Q67. J. Hazard. Mater. 190, 100-105.

Ma, X.Y., Wang, X.C., Liu, Y.J., 2012. Cytotoxicity and genotoxicity evaluation of urban surface waters using freshwater luminescent bacteria Vibrio-qinghaiensis sp.-Q67 and Vicia faba root tip. J. Environ. Sci. 24, 1861-1866.

Macken, A., Giltrap, M., Foley, B., McGovern, E., McHugh, B., Davoren, M., 2008. A model compound study: the ecotoxicological evaluation of five organic contaminants employing a battery of marine bioassays. Environ. Pollut. 153, 627637. 
Mantis, I., Voutsa, D., Samara, C., 2005. Assessment of the environmental hazard from municipal and industrial wastewater treatment sludge by employing chemical and biological methods. Ecotoxicol. Environ. Saf 62, 397-407.

Mendonca, E., Picado, A., Paixão, S.M., Silva, L., Cunha, M.A., Leitão, S., Moura, I., Cortez, C., Brito, F., 2009. Ecotoxicity tests in the environmental analysis of wastewater treatment plants: case study in Portugal. J. Hazard. Mater 163, 665670.

Ore, S., Todorovic, J., Ecke, H., Grennberg, K., Lidelöw, S., Lagerkvist, A., 2007. Toxicity of leachate from bottom ash in a road construction. Waste Manage 27, 1626-1637.

Parvez, S., Venkataraman, C., Mukherji, S., 2006. A review on advantages of implementing luminescence inhibition test (Vibrio fischeri) for acute toxicity prediction of chemicals. Environ. Int 32, 265-268.

Pérez, S., Farré, M.l., Barceló, D., 2009. Analysis, behavior and ecotoxicity of carbonbased nanomaterials in the aquatic environment. TrAC Trends Anal. Chem. 28, 820-832.

Pernet-coudrier, B., Clouzot, L., Varrault, G., Tusseau-vuillemin, M.-H., Verger, A., Mouchel, J-M., 2008. Dissolved organic matter from treated effluent of a major wastewater treatment plant: characterization and influence on copper toxicity. Chemosphere 73, 593-599.

Qu, D., Wang, J., Wang, L., Hou, D., Luan, Z., Wang, B., 2009. Integration of accelerated precipitation softening with membrane distillation for highrecovery desalination of primary reverse osmosis concentrate. Sep. Purif. Technol. 67, 21-25.

Reginatto, V., Amante, E.R., Gerhardy, K., Kunst, S., Duran, N., 2009. Biodegradation and ecotoxicological assessment of pectin production wastewater. J. Environ. Sci. 21, 1613-1619.

Roig, N., Nadal, M., Sierra, J., Ginebreda, A., Schuhmacher, M., Domingo, J.L., 2011. Novel approach for assessing heavy metal pollution and ecotoxicological status of rivers by means of passive sampling methods. Environ. Int. 37, 671-677.

Rosal, R., Rodea-Palomares, I., Boltes, K., Fernandez-Pinas, F., Leganes, F., Gonzalo, S., Petre, A., 2010. Ecotoxicity assessment of lipid regulators in water and biologically treated wastewater using three aquatic organisms. Environ. Sci. Pollut. Res. 17, 135-144.
Schneyer, L.H., 1951. The effect of low concentrations of calcium and phosphate salts on bacterial luminescence intensity. J. Cell. Physiol 37, 337-350.

Smital, T., Terzic, S., Zaja, R., Senta, I., Pivcevic, B., Popovic, M., Mikac, I., Tollefsen, K. E., Thomas, K.V., Ahel, M., 2011. Assessment of toxicological profiles of the municipal wastewater effluents using chemical analyses and bioassays. Ecotoxicol. Environ. Saf 74, 844-851.

Utgikar, V.P., Chaudhary, N., Koeniger, A., Tabak, H.H., Haines, J.R., Govind, R., 2004. Toxicity of metals and metal mixtures: analysis of concentration and time dependence for zinc and copper. Water Res. 38, 3651-3658.

Wang, C., Shi, H., Adams, C.D., Gamagedara, S., Stayton, I., Timmons, T., Ma, Y., 2011. Investigation of pharmaceuticals in Missouri natural and drinking water using high performance liquid chromatography-tandem mass spectrometry. Water Res. 45, 1818-1828.

Ye, Z., Zhao, Q., Zhang, M., Gao, Y., 2011. Acute toxicity evaluation of explosive wastewater by bacterial bioluminescence assays using a freshwater luminescent bacterium, Vibrio qinghaiensis sp. Nov. J. Hazard. Mater. 186, 1351-1354.

Zhang, Y.H., Liu, S.S., Song, X.Q., Ge, H.L., 2008. Prediction for the mixture toxicity of six organophosphorus pesticides to the luminescent bacterium Q67. Ecotoxicol. Environ. Saf 71, 880-888.

Zhou, T., Lim, T.T., Chin, S.S., Fane, A.G., 2011. Treatment of organics in reverse osmosis concentrate from a municipal wastewater reclamation plant: feasibility test of advanced oxidation processes with/without pretreatment. Chem. Eng. J. 166, 932-939.

Zhou, X.F., Sang, W.J., Liu, S.S., Zhang, Y.L., Ge, H., 2010. Modeling and prediction for the acute toxicity of pesticide mixtures to the freshwater luminescent bacterium Vibrio qinghaiensis sp.-Q67. Environ. Sci. 22, 433-440.

Zhu, X.W., Liu, S.S., Ge, H.L., Liu, Y., 2009. Comparison between the short-term and the long-term toxicity of six triazine herbicides on photobacteria Q67. Water Res. 43, 1731-1739.

Zou, X.M., Lin, Z.F., Deng, Z.Q., Yin, D.Q., Zhang, Y.L., 2012. The joint effects of sulfonamides and their potentiator on Photobacterium phosphoreum: differences between the acute and chronic mixture toxicity mechanisms. Chemosphere 86, 30-35. 